\title{
Carta Abierta
}

Sr. D. Carlos García-Prada, Editor, en Jefe de la REVISTA IBEROAMERICANA.

Muy distinguido señor:

El día de ayer llegó a mis manos su muy atenta de 22 de abril. No puedo menos de agradecer el alto honor que me hace en convidarme a publicar en la Revista Iberoamericana un artículo sobre mi viaje a los Estados Unidos. Desgraciadamente me hallo actualmente cogido por varios inaplazables compromisos, sumados a mis ocupaciones ordinatias de profesor, que no me permiten ninguna actividad suplementaria. Estoy preparando ahora la edición crítica de El Nuevo Luciano de Quito de Espejo (precursor de la independencia suramericana), e inmediatamente después tengo que emprender tomo tras tomo la publicación de las obras de Remigio Crespo Toral.

No en forma de artículo, sino únicamente para suministrar a Ud. datos que pueden serle útiles, indicaré a Ud. que la primera verdad que tendría que hacer constar, como comprobada en mi viaje a los Estados Unidos, es la necesidad de algún conocimiento mutuo si se pretende llegar a un mejor entendimiento interamericano. La verdad es que los norteamericanos ignoran casi en absoluto a sus vecinos del sur. Habiendo en tres meses visitado 12 grandes universidades, fuera de otras instituciones de estudios inferiores, y tratado exclusivamente con gente de estudios, no hallé sino a dos personas que pudieran sostener una conversación inteligente sobre el Ecuador, el Dr. Ricardo Pattee del Departamento de Estado y el Prof. Rippy de la Universidad de Chicago, especializado en histo- 
ria suramericana. No solamente faltan conocimientos geográficos, históricos y sociales, sino que falta sobre todo la convicción de que un norteamericano pueda tener algo que aprender en Suramérica.

$\mathrm{Y}$ sin embargo, sin patrioterismos necios, y reconociendo en muchísimos campos nuestro lamentable atraso, saqué la convicción de que la superioridad norteamericana en el orden espiritual es cosa algo problemática. La superioridad aplastante en el orden material no lo es todo. Las Universidades y Colegios son palacios; sus Bibliotecas, maravillosas; sus contingentes de profesores, imponentes. Pero, ¿ basta esto para dominar intelectualmente? Este Colegio de Cotocollao no es más que un Colegio secundario; y con todo hallé que nuestro curso de clásicos latinos y griegos está a la altura de los mejores cursos universitarios de Estados Unidos, y personalmente sentí que podía alternar con los profesores universitarios de allá, tanto en las conversaciones privadas con ellos como en las clases o conferencias que me pidieron para sus alumnos.

Creo sinceramente que los Estados Unidos pueden proporcionar a nuestros estudiosos incomparables instrumentos de trabajo y educarlos en la técnica del trabajo científico; pero que a su vez los estudiosos de Estados Unidos hallarán en la América del Sur un ambiente espiritual de cultura más antigua que la suya, quizá más hondamente asimilada. Al fin somos, me parece, más pobres --incomparablemente más pobres-, pero quizá no menos cultos y ciertamente no menos capaces de cultura.

Estoy seguro que un especialista en ciencias recalcaría más que yo nuestra inferioridad respecto de Estados Unidos; pero yo, especializado en letras clásicas, no sentí en forma aguda tal inferioridad. Es decir, que en un ramo de adelanto humano en que no tiene tanta importancia, como en ciencias, el material costoso, no estamos, ni con mucho, tan atrasados, demostrándose con esto que ol valor humano está más equilibrado de parte y parte en lo puramente intelectual.

Con sentimientos de viva gratitud por su atención y cortesia, quedo de Ud. muy a. y s. s.

Aurelio Espinosa Polit, S. J., Quito. 